\title{
Excess Molar Quantities of Binary Mixture of Dipropyl amine with Aliphatic Alcohols at 298.15 K
}

\section{ZAINAB A. H. AL-DULAIMY*1, DHAFIR T. A. AL-HEETIMI², HUSAM SALEEM KHALAF ${ }^{3}$ and AHMED MOHAMMED ABBAS 4}

\author{
1, 2, 3, 4 Department of Chemistry, College of Education for Pure Science-Ibn-Al-Haitham, \\ University of Baghdad, Baghdad, Iraq. \\ ${ }^{\star}$ Corresponding author E-mail: zainabaldialamy@yahoo.com
}

http://dx.doi.org/10.13005/ojc/3404047

(Received: April 03, 2018; Accepted: June 26, 2018)

\begin{abstract}
Refractive indices $\left(n_{D}\right)$, viscosities $(\eta)$ and densities $(\rho)$ were deliberated for the binary mixtures created by dipropyl amine with 1-octanol, 1-heptanol, 1-hexanol, 1-pentanol and tert-pentyl alcohol at temperature $298.15 \mathrm{~K}$ over the perfect installation extent. The function of Redlich-Kister were used to calculate and renovated of the refractive index deviations $\left(\Delta n_{D}\right)$, viscosity deviations $\left(\eta^{\mathrm{E}}\right)$, excess molar Gibbs free energy $\left(\Delta \mathrm{G}^{*} \mathrm{E}\right)$ and excess molar volumes $\left(\mathrm{V}_{\mathrm{m}}^{\mathrm{E}}\right)$. The standard errors and coefficients were respected by this function. The values of $\Delta n_{D}, \eta^{E}, V_{m}{ }^{E}$ and $\Delta G^{* E}$ were plotted against mole fraction of dipropyl amine. In all cases the obtained $\eta^{\mathrm{E}}, \Delta \mathrm{G}^{*}, \mathrm{~V}_{m}{ }^{\mathrm{E}}$ and $\Delta \mathrm{n}_{\mathrm{D}}$ values were negative at $298.15 \mathrm{~K}$. Effect of carbon atoms number in the chain of alcohol and hydroxyl groups' position on molecular interactions in these mixtures has also been discussed.
\end{abstract}

Keywords: Binary system, Aliphatic alcohols, Dipropylamine, Viscosity, Refractive index, Density and Excess properties.

\section{INTRODUCTION}

The familiarity of the excess parameters of organic liquid blends is salutary in industrial enforcements and is highly significant for understanding the molecular interactions between the components this as well assist to develop theoretical patterns ${ }^{1-3}$. The experimental conclusions are adduced in this paper for the binary system of dipropyl amine with 1-alkanols and tert-pentyl alcohol at $298.15 \mathrm{~K}$. These conclusions expose the cross-association between alkanol and amine molecules down the identical conditions ${ }^{4-6}$. Also the conclusions display the steric hindrance of methyl groups. Alcohols are polar and self-associated through hydrogen bonding in the state alcohols are multilateral solvents used in the division of saturated and unsaturated hydrocarbons and in medicinal synthesis and serve as solvents for numerous polymers ${ }^{7}$. A survey of the literature detects sundry on the excess properties of binary mixtures including amines and alcohols ${ }^{8-13}$. The thermodynamic properties of multicomponent systems are some major parameters for the layout and optimization of 
chemical process. Although many surveys on density and viscosity have been recorded ${ }^{14-15}$.

Alcohols are highly paramount solvents in a numeral of processing procedures and have sundry enforcements as reagents or solvents, hand sanitizers, antifreeze, and antiseptics as well as keeper in learning and métier ${ }^{16}$. Amines are compounds contain on basic nitrogen atom carried a lone pair. Derivatives of ammonia are known amines, which contains one or more hydrogen atoms have been replaced by substituent such as an alkyl or aryl group. Amines are highly paramount several enforcement for example; dipropyl amine is a secondary amine whose belongs to the class of dialkyl amines. It is multilateral medium with a diversity of enforcements. Most paramount enforcements are found in the field of agricultural chemicals; however, also substantial volumes are

wasted for the produce of other non- agricultural chemicals.

\section{EXPERIMENTAL}

\section{Liquid materials}

The following liquid materials were used are:

\begin{tabular}{llr}
$\begin{array}{l}\text { Name of } \\
\text { material }\end{array}$ & $\begin{array}{c}\text { Chemical } \\
\text { formula }\end{array}$ & $\begin{array}{c}\text { Purity } \\
\text { Name of } \\
\text { company }\end{array}$ \\
\hline Dipropyl amine & $\mathrm{C}_{6} \mathrm{H}_{15} \mathrm{~N}$ & $99 \%$ Aldrich \& Co \\
1-Pentanol & $\mathrm{C}_{5} \mathrm{H}_{12} \mathrm{O}$ & $99 \%$ Aldrich \& Co \\
1-Hexanol & $\mathrm{C}_{6} \mathrm{H}_{14} \mathrm{O}$ & $98 \%$ Aldrich \& Co \\
1-Heptanol & $\mathrm{C}_{7} \mathrm{H}_{16} \mathrm{O}$ & $98 \%$ Aldrich \& Co \\
1-Octanol & $\mathrm{C}_{8} \mathrm{H}_{18} \mathrm{O}$ & $99 \%$ Aldrich \& Co \\
tert-Pentyl alcohol & $\mathrm{C}_{5} \mathrm{H}_{12} \mathrm{O}$ & $98 \%$ Aldrich \& Co \\
\hline
\end{tabular}

\section{Chemicals}

Table 1: Comparison of experimental, viscosities $(\eta)$, densities $(\rho)$ and refractive index $\left(n_{D}\right)$ of pure liquids with literature data at $298.15 \mathrm{~K}$.

\begin{tabular}{|c|c|c|c|c|c|c|}
\hline \multirow[t]{2}{*}{ Liquid } & \multicolumn{2}{|c|}{$\eta$ (mpas) } & \multicolumn{2}{|c|}{$\rho\left(\right.$ g.cm $\left.{ }^{-3}\right)$} & \multicolumn{2}{|c|}{$\mathrm{n}_{\mathrm{D}}$} \\
\hline & Experimental & Literature & Experimental & Literature & Experimental & Literature \\
\hline Dipropyl amine & 0.51734 & $0.50685^{17}$ & 0.73825 & $\begin{array}{c}0.73133^{18} \\
0.73564^{19} \\
0.7333^{62}\end{array}$ & 1.40362 & $1.40184^{19}$ \\
\hline 1-Pentanol & 3.5411 & $\begin{array}{l}3.53441^{21} \\
3.53241^{22} \\
3.34785^{23}\end{array}$ & 0.81084 & $\begin{array}{l}0.81083^{24} \\
0.81076^{25} \\
0.81072^{22}\end{array}$ & 1.40812 & $\begin{array}{l}1.40781^{24} \\
1.40823^{26} \\
1.40953^{27}\end{array}$ \\
\hline 1-Hexanol & 4.59242 & $\begin{array}{l}4.59324^{28} \\
4.59112^{29}\end{array}$ & 0.81503 & $\begin{array}{c}0.81523^{28} \\
0.8152^{23}\end{array}$ & 1.41775 & $1.41589^{31}$ \\
\hline 1-Heptanol & 5.94435 & $\begin{array}{l}5.94432^{32} \\
6.00162^{28}\end{array}$ & 0.81876 & $\begin{array}{l}0.81873^{32} \\
0.81879^{28}\end{array}$ & 1.41987 & $\begin{array}{l}1.42254^{33} \\
1.42262^{32}\end{array}$ \\
\hline 1-Octanol & 7.66058 & $\begin{array}{l}7.59812^{28} \\
7.66153^{32}\end{array}$ & 0.82165 & $\begin{array}{l}0.82172^{33} \\
0.82182^{29}\end{array}$ & 1.42645 & $\begin{array}{l}1.42835^{34} \\
1.42823^{24}\end{array}$ \\
\hline tert-Pentyl alcohol & 3.52642 & $\begin{array}{l}3.53346^{35} \\
3.54825^{36}\end{array}$ & 0.80447 & $\begin{array}{c}0.804337^{35} \\
0.80507^{36}\end{array}$ & 1.40186 & $\begin{array}{l}1.40237^{35} \\
1.40246^{24}\end{array}$ \\
\hline
\end{tabular}

\section{Density measurement}

Densities of pure components and liquidliquid mixtures were measured with an Anton paar digital densimeter (Model DMA 60/602) with an accuracy of $\pm 10^{-5} \mathrm{~g} \cdot \mathrm{cm}^{-3}$. Air and double distilled water used for the calibration of the densimeter. At least three times for each composition in experimental were generally repeated and the results were treatment.

\section{Viscosities measurements}

By using a suspended-level ubbelohde viscometer in a bath controlled to $\pm 0.01 \mathrm{~K}$ at 298.15 $\mathrm{K}$ was determined the viscosities. To give the final values the experimental were repeated at least three times and the results were corrected.

\section{Refractive index measurements}

By using a digital Abbe refractometer (Model: BOE 32400) were determined the refractive 
indices of pure components and their liquid-liquid mixtures. The measuring refractive indices of double distilled water and toluene were used to calibrate the refractometer at $298.15 \mathrm{~K}$.

\section{RESULTS AND DISCUSSION}

Table 2 shows experimental viscosities, densities, refractive indices, deviation in viscosity, excess volumes, refractive index deviation and excess molar Gibbs free energy for five binary systems dipropyl amine with some alcohols and tert-pentyl alcohol at 298.15 K.

The excess molar volumes $\left(\mathrm{V}_{\mathrm{m}}{ }^{\mathrm{E}}\right)$ were matured from density data according to:

$$
V_{m}^{E}=\sum_{i=1}^{N} X_{i} M_{i}\left(\rho^{-1}-\rho_{i}^{-1}\right)
$$

Where $\rho_{i}, X_{i}$ and $\mathrm{Mi}$ are the density, mole fraction and molar mass of the component $i, \rho$ is the density of mixtures, $n$ is the number of components.

Table 2: Densities $\rho$, viscosities $\eta$, refractive index $n_{D}$, excess molar volumes $V_{m}{ }^{E}$, viscosity deviations $\eta^{\mathrm{E}}$, excess molar Gibbs free energy $\Delta \mathrm{G}^{\star \mathrm{E}}$ and refractive index deviation $\Delta \mathrm{n}_{\mathrm{D}}$ of dipropylamine and alcohols at $298.15 \mathrm{~K}$

\begin{tabular}{|c|c|c|c|c|c|c|c|}
\hline \multirow[b]{2}{*}{$\mathrm{X}_{1}$} & \multicolumn{7}{|c|}{ Dipropylamine + 1-pentanol } \\
\hline & $\rho\left(\mathrm{g} \mathrm{cm}^{-3}\right)$ & $\mathrm{V}_{\mathrm{m}}^{\mathrm{E}}\left(\mathrm{cm}^{3} \cdot \mathrm{mole}^{-1}\right)$ & $\mathrm{n}_{\mathrm{D}}$ & $\Delta \mathrm{n}_{\mathrm{D}}\left(\mathrm{cm}^{3} \mathrm{~mole}^{-1}\right)$ & $\eta$ (map.s) & $\eta^{E}$ (mpa.s) & $\Delta \mathrm{G}^{\star \mathrm{E}}\left(\mathrm{kj} \cdot \mathrm{mole}^{-1}\right)$ \\
\hline 0.0000 & 0.81084 & 0.0000 & 1.40812 & 0.0000 & 3.53411 & 0.0000 & 0.0000 \\
\hline 0.1023 & 0.80304 & -0.18339 & 1.40711 & -0.18198 & 2.79173 & -0.03923 & -0.09073 \\
\hline 0.1989 & 0.79666 & -0.48158 & 1.40699 & -0.26683 & 2.20124 & -0.09125 & -0.21509 \\
\hline 0.2760 & 0.79223 & -0.72726 & 1.40685 & -0.31225 & 1.84520 & -0.11953 & -0.28256 \\
\hline 0.3698 & 0.78665 & -1.01336 & 1.40678 & -0.33301 & 1.52964 & -0.12685 & -0.29865 \\
\hline 0.5020 & 0.78081 & -1.66832 & 1.40606 & -0.35115 & 1.17818 & -0.13389 & -0.31529 \\
\hline 0.5976 & 0.77225 & -1.42027 & 1.40562 & -0.33262 & 0.99412 & -0.11998 & -0.28187 \\
\hline 0.7824 & 0.75485 & -0.60369 & 1.40392 & -0.28168 & 0.71839 & -0.08981 & -0.21178 \\
\hline 0.8134 & 0.75349 & -0.40939 & 1.40388 & -0.24816 & 0.69255 & -0.06687 & -0.15615 \\
\hline 0.9432 & 0.74247 & -0.16618 & 1.40364 & -0.08815 & 0.55995 & -0.02998 & -0.07103 \\
\hline 1.0000 & 0.73825 & 0.0000 & 1.40362 & 0.0000 & 0.51734 & 0.0000 & 0.0000 \\
\hline
\end{tabular}

Dipropylamine + 1-hexanol

\begin{tabular}{lccccccc}
\hline $\mathrm{X}_{1}$ & $\rho\left(\mathrm{g} \mathrm{cm}^{-3}\right)$ & $\mathrm{V}_{\mathrm{m}}{ }^{\mathrm{E}}\left(\mathrm{cm}^{3} \cdot \mathrm{mole}^{-1}\right)$ & $\mathrm{n}_{\mathrm{D}}$ & $\Delta \mathrm{n}_{\mathrm{D}}\left(\mathrm{cm}^{3} \mathrm{~mole}^{-1}\right)$ & $\eta(\mathrm{mpa} . \mathrm{s})$ & $\eta^{\mathrm{E}}(\mathrm{mpa} . \mathrm{s})$ & $\Delta \mathrm{G}^{\star E}\left(\mathrm{kj}^{\left.\mathrm{m} \cdot \mathrm{mole}^{-1}\right)}\right.$ \\
\hline 0.0000 & 0.81503 & 0.0000 & 1.41775 & 0.0000 & 4.59242 & 0.0000 & 0.0000 \\
0.0963 & 0.80805 & -0.16181 & 1.41362 & -0.19308 & 3.53586 & -0.05118 & -0.12509 \\
0.2067 & 0.80005 & -0.32685 & 1.41081 & -0.27377 & 2.62279 & -0.10884 & -0.26817 \\
0.3192 & 0.79223 & -0.52383 & 1.40882 & -0.32114 & 2.00411 & -0.13225 & -0.32562 \\
0.4009 & 0.78705 & -0.73774 & 1.40722 & -0.35613 & 1.61593 & -0.16914 & -0.41689 \\
0.5104 & 0.77992 & -1.41890 & 1.40565 & -0.36436 & 1.21287 & -0.21698 & -0.53538 \\
0.5983 & 0.77449 & -1.20197 & 1.40471 & -0.34233 & 1.02298 & -0.19532 & -0.48182 \\
0.6842 & 0.76421 & -0.55365 & 1.40412 & -0.29843 & 0.89202 & -0.14478 & -0.35668 \\
0.8032 & 0.75448 & -0.38876 & 1.40364 & -0.21049 & 0.69967 & -0.12779 & -0.31525 \\
0.9134 & 0.74543 & -0.19249 & 1.40363 & -0.09603 & 0.57572 & -0.08216 & -0.20294 \\
1.0000 & 0.73825 & 0.0000 & 1.40362 & 0.0000 & 0.51734 & 0.0000 & 0.0000
\end{tabular}




\begin{tabular}{lccccccc}
\hline \multicolumn{7}{c}{ Dipropylamine + 1-heptanol } \\
\hline $\mathrm{X}_{1}$ & $\rho\left(\mathrm{g} \mathrm{cm}^{-3}\right)$ & $\mathrm{V}_{\mathrm{m}}{ }^{\mathrm{E}}\left(\mathrm{cm}^{3} \cdot \mathrm{mole}^{-1}\right)$ & $\mathrm{n}_{\mathrm{D}}$ & $\Delta \mathrm{n}_{\mathrm{D}}\left(\mathrm{cm}^{3} \mathrm{~mole}^{-1}\right)$ & $\eta(\mathrm{mpas})$ & $\eta^{\mathrm{E}}(\mathrm{mpas})$ & $\Delta \mathrm{G}^{\mathrm{E}}\left(\mathrm{kj} . \mathrm{mole}^{-1}\right)$ \\
\hline 0.0000 & 0.81876 & 0.0000 & 1.41987 & 0.0000 & 5.94435 & 0.0000 & 0.0000 \\
0.0918 & 0.81244 & -0.14637 & 1.41465 & -0.28905 & 4.24546 & -0.11246 & -0.27867 \\
0.2033 & 0.80468 & -0.32199 & 1.41185 & -0.37162 & 2.96688 & -0.19857 & -0.49199 \\
0.3095 & 0.79715 & -0.47790 & 1.40976 & -0.40419 & 2.01857 & -0.32441 & -0.80383 \\
0.4166 & 0.78984 & -0.69812 & 1.40773 & -0.42831 & 1.38273 & -0.44126 & -1.09342 \\
0.5059 & 0.78488 & -1.09271 & 1.40615 & -0.43801 & 1.05941 & -0.48957 & -1.21323 \\
0.5860 & 0.77599 & -0.66799 & 1.40509 & -0.41849 & 0.93833 & -0.41537 & -1.02926 \\
0.6974 & 0.76545 & -0.40583 & 1.40408 & -0.35380 & 0.79445 & -0.30986 & -0.76772 \\
0.8259 & 0.75399 & -0.24066 & 1.40377 & -0.21445 & 0.65932 & -0.18256 & -0.45231 \\
0.9069 & 0.74666 & -0.12423 & 1.40365 & -0.11902 & 0.58778 & -0.09965 & -0.24689 \\
1.0000 & 0.73825 & 0.0000 & 1.40362 & 0.0000 & 0.51734 & 0.0000 & 0.0000 \\
\hline
\end{tabular}

Dipropylamine + 1-octanol

\begin{tabular}{lccccccc}
\hline $\mathrm{X}_{1}$ & $\rho\left(\mathrm{g} \mathrm{cm}^{-3}\right)$ & $\mathrm{V}_{\mathrm{m}}{ }^{\mathrm{E}}\left(\mathrm{cm}^{3} \cdot \mathrm{mole}^{-1}\right)$ & $\mathrm{n}_{\mathrm{D}}$ & $\Delta \mathrm{n}_{\mathrm{D}}\left(\mathrm{cm}^{3} \mathrm{~mole}^{-1}\right)$ & $\eta(\mathrm{mpa} . \mathrm{s})$ & $\eta^{\mathrm{E}}(\mathrm{mpa} . \mathrm{s})$ & $\Delta \mathrm{G}^{\mathrm{E}}\left(\mathrm{kj} . \mathrm{mole}^{-1}\right)$ \\
\hline 0.0000 & 0.82165 & 0.0000 & 1.42645 & 0.0000 & 7.66058 & 0.0000 & 0.0000 \\
0.0976 & 0.81505 & -0.10235 & 1.42141 & -0.33971 & 4.25221 & -0.32561 & -0.80490 \\
0.1991 & 0.80812 & -0.23419 & 1.41911 & -0.43279 & 2.81785 & -0.46351 & -1.14490 \\
0.3014 & 0.80105 & -0.39128 & 1.41705 & -0.46881 & 1.86003 & -0.60318 & -1.48977 \\
0.3975 & 0.79421 & -0.53960 & 1.41001 & -0.49983 & 1.32479 & -0.68352 & -1.68810 \\
0.4982 & 0.78679 & -0.68898 & 1.40825 & -0.52734 & 0.9438 & -0.75121 & -1.85559 \\
0.5987 & 0.77784 & -0.59433 & 1.40701 & -0.49186 & 0.84889 & -0.58632 & -1.44708 \\
0.6954 & 0.76799 & -0.31784 & 1.40567 & -0.44746 & 0.74136 & -0.46115 & -1.13748 \\
0.8011 & 0.75794 & -0.20262 & 1.40441 & -0.35821 & 0.65756 & -0.29622 & -0.72999 \\
0.8984 & 0.74848 & -0.10811 & 1.40388 & -0.20527 & 0.60956 & -0.10979 & -0.26966 \\
1.0000 & 0.73825 & 0.0000 & 1.40362 & 0.0000 & 0.51734 & 0.0000 & 0.0000 \\
\hline
\end{tabular}

Dipropylamine + tert-pentyl alcohol

\begin{tabular}{|c|c|c|c|c|c|c|c|}
\hline$X_{1}$ & $\rho\left(\mathrm{g} \mathrm{cm}^{-3}\right)$ & $\mathrm{V}_{\mathrm{m}}{ }^{\mathrm{E}}\left(\mathrm{cm}^{3} \cdot \mathrm{mole}^{-1}\right)$ & $\mathrm{n}_{\mathrm{D}}$ & $\Delta \mathrm{n}_{\mathrm{D}}\left(\mathrm{cm}^{3} \mathrm{~mole}^{-1}\right)$ & $\eta$ (mpa.s) & $\eta^{E}$ (mpa.s) & $\Delta G^{\star E}\left(k j \cdot\right.$ mole $\left.^{-1}\right)$ \\
\hline 0.0000 & 0.80447 & 0.0000 & 1.40186 & 0.0000 & 3.52642 & 0.0000 & 0.0000 \\
\hline 0.0910 & 0.79747 & -0.05195 & 1.40281 & -0.09327 & 2.92724 & -0.01157 & -0.02320 \\
\hline 0.1967 & 0.79155 & -0.13254 & 1.40305 & -0.20991 & 2.35395 & -0.02669 & -0.05580 \\
\hline 0.3056 & 0.78334 & -0.35867 & 1.40315 & -0.29535 & 1.86591 & -0.04998 & -0.11036 \\
\hline 0.3724 & 0.77989 & -0.55792 & 1.40329 & -0.32221 & 1.61414 & -0.06672 & -0.15061 \\
\hline 0.5036 & 0.77138 & -0.63133 & 1.40342 & -0.34182 & 1.2476 & -0.07248 & -0.16422 \\
\hline 0.5924 & 0.76454 & -0.45953 & 1.40344 & -0.32979 & 1.06688 & -0.05853 & -0.13031 \\
\hline 0.7093 & 0.75625 & -0.28299 & 1.40348 & -0.27930 & 0.87032 & -0.03778 & -0.08127 \\
\hline 0.7991 & 0.74998 & -0.11369 & 1.40358 & -0.21097 & 0.74207 & -0.02485 & -0.05208 \\
\hline 0.9111 & 0.7433 & -0.04679 & 1.4036 & -0.10506 & 0.60699 & -0.01082 & -0.02208 \\
\hline 1.0000 & 0.73825 & 0.0000 & 1.40362 & 0.0000 & 0.51734 & 0.0000 & 0.0000 \\
\hline
\end{tabular}


The values of excess molar volumes are shown in Figure 1.

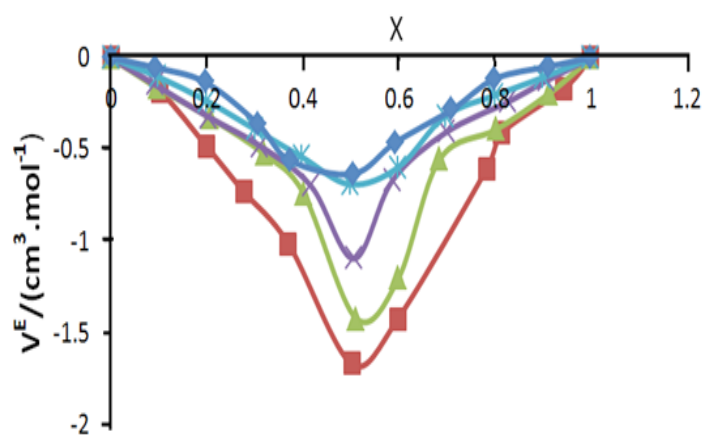

Fig. 1. Curves of excess molar volumes $\left(V^{E}\right)$ Vs mole fraction $\left(X_{1}\right)$ for the binary mixtures of dipropylamine+1-pentanol $(\square)$, 1-hexanol $(\Delta)$, 1-heptanol $(x), 1$-octanol $\left({ }^{*}\right)$ and tert-pentyl -alcohol( $\bullet)$, at 298.15K

The excess molar volumes $\mathrm{V}_{\mathrm{m}} \mathrm{E}$, inspected in project were all negative over the whole range of dipropylamine composition at $298.15 \mathrm{~K}$. These are shown in Fig. 1. This may suggest that volume construction takes place onto mixing dipropylamine with alcohols due to the cross-association between these various molecules ${ }^{37}$.

And the negative values are attributable mainly to the association between amine and alcohols intermolecular hydrogen bonds between the $-\mathrm{OH}$ groups in alcohols and the nitrogen atoms in the amine. The strength of the associations arising from interactions between the unlike molecules was stronger than the strength of the association between like molecules ${ }^{38}$. The magnitude of the volume contraction follows the sequence of:

1-pentanol $>1$-hexanol $>1$-heptanol $>1$-octanol $>$ ter-pentyl alcohol

The viscosity deviations $\left(\eta^{E}\right)$ for two compound mixtures can be calculated as:

$\eta^{\mathrm{E}}=\eta-\sum_{\mathrm{i}}^{\mathrm{N}}=_{1} \mathrm{X}_{\mathrm{i}} \eta_{\mathrm{i}}$

Where $\eta_{i}$ is the absolute viscosity of pure component $i$ and $\eta$ is the absolute viscosity of the mixtures. The $\left(\eta^{E}\right)$ values are also graphically represented as a function of mole fraction at 298.15 $\mathrm{K}$ in Figure 2.

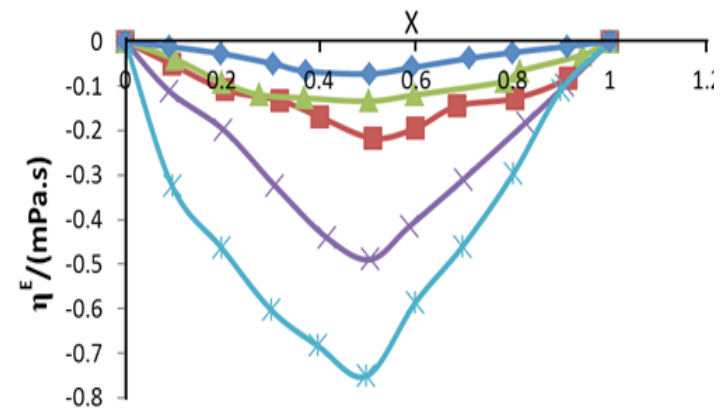

Fig. 2.Curves of viscosity devation $\left(\eta^{\mathrm{E}}\right)$ Vs mole fraction $\left(\mathbf{X}_{1}\right)$ for the binary mixtures of dipropylamine+1-hexanol $(\square)$, 1-pentanol $(\Delta)$, 1-heptanol $(\times)$, 1-octanol $\left(^{*}\right)$ and tert-pentyl-alcohol( $\bullet)$, at 298.15K

Excess molar Gibbs free energy of activation of viscous flow was acquired by using:

$\Delta G^{\star E}=R T\left[\ln \left(\eta_{m} V_{m}\right)-\left(X_{1} \ln \eta_{1} V_{1}\right)-\left(X_{2} \ln \eta_{2} V_{2}\right)\right]$

Where $R$ is the universal constant of gases, $T$ is a Kelvin temperature, $X_{1}, X_{2}$ represent mole fraction of component 1 and $2, V_{1}, V_{2}$ are the molar volumes of component 1 and 2 , and $\eta_{1}, \eta_{2}$ and $\eta_{m}$ are the viscosity of component 1,2 and viscosity of mixture respectively.

$V_{m}$ is obtained from equation:

$\mathrm{V}_{\mathrm{m}}=\left(\mathrm{X}_{1} \mathrm{~V}_{1}+\mathrm{X}_{2} \mathrm{~V}_{2}\right) / \rho_{\mathrm{m}}$

The values excess molar Gibbs free energy is shown in Figure 3.

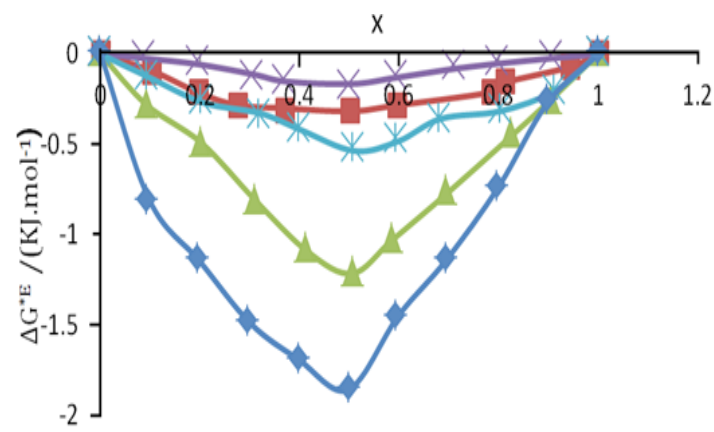

Fig. 3. Curves of excess molar Gibbs free energy $\left(\Delta G^{*}\right)$ Vs mole fraction $\left(X_{1}\right)$ for the binary mixtures of dipropylamine+1-pentanol( $\square), 1$-heptanol $(\Delta)$, tertpentylalcohol $(\times), 1-$ hexanol $\left({ }^{*}\right)$ and 1-octanol $(\bullet)$, at 298.15K

The viscosity deviations $\left(\eta^{\mathrm{E}}\right)$, Fig. 2 and excess molar Gibbs energy $\left(\Delta G^{*}\right)$, Fig. 3 are negative over the whole mole fraction range at $298.15 \mathrm{~K}$. These results can be attributed to the laceration of hydrogen bonded between dipropylamine and alcohols which overtake on 
dipole-dipole molecular interaction between them and become less positive as the length of alkanol chain increased. The necessitation values of deviation in viscosity and excess molar Gibbs free energy for binary liquid mixtures fall in the order:

1-octanol >1-heptanol >1-hexanol >1-pentanol >ter-pentyl alcohol by Brocos et al., ${ }^{36}$ were calculated the deviation of refractive index $\left(\Delta n_{D}\right)$ from the volume fraction average:

$\Delta \mathrm{n}_{\mathrm{D}}=\mathrm{n}_{\mathrm{D}}-\sum_{\mathrm{i}=1}^{\mathrm{N}} \varphi_{\mathrm{i}} \mathrm{n}_{\mathrm{Di}}$

$\left.\varphi_{i}=X_{i} V_{i} / \sum_{i=1}^{N} X_{i} V_{i}\right)$

Where $\varphi_{i}, n_{D}$, and $n_{D i}$ are the volume fraction, refractive index of mixture, the density of

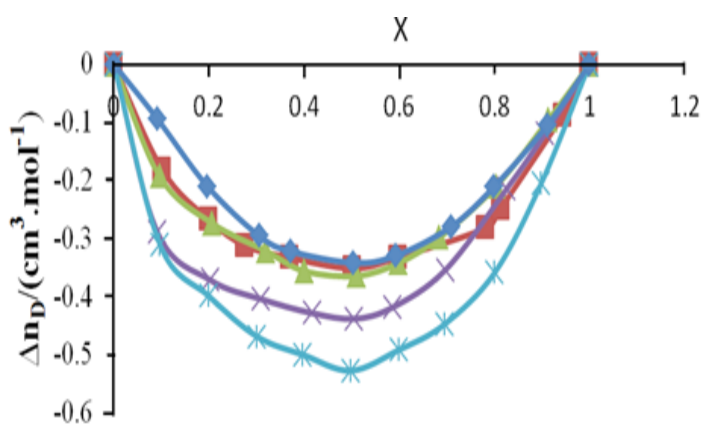

Fig. 4. Curves of refractive index devation $\left(\Delta n_{D}\right)$ Vs mole fraction $\left(X_{1}\right)$ for the binary mixtures of dipropylamine+1pentanol $(\square)$, 1-hexanol $(\Delta)$, 1-heptanol $(\times)$, 1-octanol $\left({ }^{*}\right)$ and tert-pentyl -alcohol $(\bullet)$, at $298.15 \mathrm{~K}$ the mixture and refractive index of pure component i respectively. $V$ and $V_{i}$ are the molar volume of the mixture and molar volume of pure component $i$ respectively. The values of $\Delta n_{D}$ are shown in Figure 4.

The values of refractive index deviation $\left(\Delta n_{D}\right)$ for the system containing dipropylamine and alcohols are negative values, Fig. 4. These values are due to hetero association of unlike molecules which give rise to formation of cross complexes where $\mathrm{O}-\mathrm{H}-\mathrm{N}$ bonds of the mixtures are stronger than $\mathrm{O}-\mathrm{H}-\mathrm{O}$ and $\mathrm{N}-\mathrm{H}-\mathrm{N}$ bonds of the single component solvents. In case of dipropylamine-ter-pentyl alcohol mixtures $\left(\Delta n_{D}\right)$ give lowest negative values such behavior may be explained qualitatively by crowdies of methyl groups around the active site of alcohol $(\mathrm{OH})$ and $\left(\Delta \mathrm{n}_{\mathrm{D}}\right)$ for these binary mixtures follows the sequence of:

1-octanol >1-heptanol >1-hexanol >1-pentanol > ter-pentyl alcohol

The $\Delta G^{*}, \eta^{E}, n_{D}$, and $V_{m}{ }^{E}$ values were fitted to a Redlich-Kister- type [39] polynomial equation:

$Y=X_{i} X_{j} \sum_{k=0}^{p} A_{k}\left(X_{i}-X_{j}\right)^{k}$

Where $Y$ is $\Delta G^{\star} E, \eta^{E}, n_{D}$, and $V_{m}{ }^{E}$ and $p$ is a degree of polynomial expansion. Standard deviations were calculated by means of the equation:

Table 3: Parameters standard deviation of equation 7 and 8 for dipropylamine + alkanols at $298.15 \mathrm{~K}$

\begin{tabular}{|c|c|c|c|c|c|}
\hline System & & $A_{0}$ & $A_{1}$ & $\mathrm{~A}_{2}$ & $\sigma$ \\
\hline \multirow[t]{3}{*}{ Dipropylamine+1-octanol } & & -2.44097 & 0.148396 & 2.795911 & 0.06421 \\
\hline & $\eta_{E}$ & -2.75230 & 1.038491 & 0.885666 & 0.04509 \\
\hline & $\Delta G^{*} E$ & -6.79637 & 2.575367 & 2.195665 & 0.07098 \\
\hline \multirow{3}{*}{ Dipropylamine+1-heptanol } & & -2.01773 & 0.415549 & -1.36639 & 0.01812 \\
\hline & & & 0.172151 & 3.680239 & 0.08654 \\
\hline & $\Delta \mathfrak{\eta}^{\mathrm{E}}$ & $\begin{array}{l}-1.80056 \\
-4.46177\end{array}$ & $\begin{array}{l}0.009326 \\
0.023272\end{array}$ & $\begin{array}{l}1.257793 \\
3.117813\end{array}$ & $\begin{array}{l}0.04814 \\
0.07580\end{array}$ \\
\hline \multirow{4}{*}{ Dipropylamine+1-hexanol } & $\Delta \mathrm{n}_{\mathrm{D}}$ & 89 & 926 & -0.755443 & 0.03860 \\
\hline & & & & & 0.11518 \\
\hline & $\eta^{\mathrm{E}}$ & -0.755944 & -0.159739 & 0.096060 & 0.03269 \\
\hline & & 389 & -0.3 & 0. & $\begin{array}{l}0.05141 \\
0.02524\end{array}$ \\
\hline \multirow[t]{3}{*}{ Dipropylamine+1-pentanol } & & -5.85815 & -0.674100 & 7.409172 & 0.0017 \\
\hline & $\eta_{G^{E}}^{E}$ & $\begin{array}{l}-0.536023 \\
-126255\end{array}$ & 0.060830 & 0.044138 & 0.00783 \\
\hline & $\Delta \mathrm{n}$ & -1.38495 & 0.057135 & -0.751003 & 0.02726 \\
\hline \multirow[t]{3}{*}{ opylamine+ter-pentyl alcoh } & & -2.28249 & 0.304666 & 3.523535 & 0.07039 \\
\hline & $\begin{array}{c}\eta^{\mathrm{E}} \\
\Delta \mathrm{G}^{\mathrm{E}}\end{array}$ & $\begin{array}{l}-0.272259 \\
-0.612963\end{array}$ & $\begin{array}{c}0.0374112 \\
0.087126\end{array}$ & $\begin{array}{l}0.272345 \\
0.676092\end{array}$ & $\begin{array}{l}0.01882 \\
0.02966\end{array}$ \\
\hline & $\Delta \mathrm{n}^{\mathrm{D}}$ & -1.38513 & 0.002102 & 0.194445 & 0.01812 \\
\hline
\end{tabular}


$\delta=\left[\sum \frac{\left(\mathrm{X}_{\mathrm{Cal}}^{\mathrm{E}}-\mathrm{X}_{\exp }^{\mathrm{E}}\right)^{2}}{m-\mathrm{n}}\right]^{0.5}$

Where $(m)$ is a number of data points and (n) are a number of estimated parameters. Values of these coefficients and the standard deviation are given in Table 3.

\section{CONCLUSION}

The densities, viscosities and refractive index of liquid-liquid mixtures of dipropylamine with 1-octanol, 1-heptanol, 1-hexanol, 1-pentanol and tert-pentyl alcohol at $298.15 \mathrm{~K}$ were measured.
The $V_{m}{ }_{m}, \Delta n_{D}, \Delta G^{* E}$ and $\eta^{E}$ were acquired from experimental data and were correlated using Redlich-Kister Polynomial equation. The results assure what has been formerly announced that in the solvents systems investigated, the negative values are attributable to stronger hydrogen bond formations between unlike molecules than those between like molecules and become less positive as the length of alkanol chain increased.

\section{ACKNOWLEDGMENT}

The author wants to show her gratitude to the university for their assistance in this work.

\section{REFERENCES}

1. Ali, A., Nain, A.K., Sharma V.K. and Ahmed, S., "Ultrasonic studies in binary liquids mixtures", Indian J. of Physics., 2001, 75B, 519-525.

2. Pal, A. and Kumar, H., "Excess molar volumes and viscosities for binary mixtures of (polyether + ester) with systems at (298.15, 308.15 and 318.15) K", Fluid Phase Equilibra., 2001, 181, 17-32.

3. Pal, A. and Kumar, H., "General physics-speed of sound and isentropic compressiblities of mixtures containing dipropylene glycol monomethyl ether and n-alkanols at $298.15 \mathrm{~K}$ ", Indian Journal of Physics., 2001, 75B, 419.

4. Wankhede, D.S., Lande, M.K. and Arbad, B.R., "Densities and viscosities of binary mixtures of paraldehyde + propylene carbonate at (288.15, 293.15, 298.15, 303.15 and 308.15) K", J. Chem. Eng. Data., 2005, 50, 26-263.

5. Wankhede, D.S., Wankhede, N.N.; Lande, M.K. and Arbad, B.R., "Molecular interactions in propylene carbonate + n-alkanols", J. Solution Chem., 2005, 34, 239-250.

6. Wankhede, N.N., Lande, M.K. and Arbad, B.R., "Excess molar volumes and viscosity deviations of binary mixtures of 2,4,6-trimethyl1,3,5-trioxane + ethanol + 1-propanol, and + 1-butanol at (298.15, 303.15 and 308.15) K", J. Chem. Eng. Data., 2005, 50, 969-972.

7. Dakua, V.K., Sinha, B. and Roy, M.N., "Thermophysiccal properties of N-Ndimethylformamide with isomeric butanols at $(298.15,308.15$ and 318.15$) \mathrm{K}$ ", J. Ind. Chem. Soc., 2007, 24, 37-45.

8. Patil, P.P., Patil, S.R., Borse, A.U. and
Hundiwale, D.G., "Densities, excess molar volume and apparent molar volume of binary liquid mixtures", Rassayan Journal of Chemistry., 2011, 4(3), 599-604.

9. Oswal, S.L. and Desail, H.S., "Studies of viscosity and excess molar of binary mixtures, 1-alkanol + tri-n-butylamine mixtures at 303.15 and 313.15 K", Fluid Phase Equilibria., 2003, 204(2), 281-294.

10. Oswal, S.L. and ljardar, S.P., "Studies of partial molar volumes of alkylamine in non-electrolyte solvents III: alkylamines in butanols at $303.15 \mathrm{~K}$ ", Journal of Molecular Liquids., 2009, 144(3), 115-123.

11. Dubey, G.P and Kumar, K., "Studies of thermophysical properties of binary mixtures of amine and alcohols at various temperatures", Journal of Thermodynamic., 2012, 50, 7-14.

12. Ahmed, S.S., Yaqub, M. and Karim, A., "Studies on three excess properties of binary liquid mixtures of 1-butylamine with some alcohols at two different temperatures", Journal of Natural Sciences and Mathematics, 2006, 46, 21-32.

13. Singh, S., Parveen, S., Shukla, D., Gupta, M. and Shukla, J.P., "Volumetric, optical, acoustical and viscometric study of molecular association in binary mixtures of butylamine with 1-butanol and tert-butanol", Acta Physica Polonica., 2007, 111(6), 847-858.

14. Rayer, A.V., Kadiwala, S., Narayanaswamy, K. and Henni, A., "Volumetric properties, viscosities and refractive index for aqueous 1-amino-2-propanol (monoisopropanolamine) solution from (298.15 to 343.15) K", Journal Chem. Eng. Data., 2010, 55, 5562-5568. 
15. Fu, D., Hao, H. and Liu, F., "Experiment and model for the viscosity of amino-2-methyl-1propanol-diethanolamine aqueous solution", Journal Mol. Liq., 2013, 188, 37-41.

16. Pal, A., Kumar, H., Maan, R. and Sharma, K., "Volumetric and acoustic studies of binary liquids mixtures of dipropylene glycol dimethyl ether with methyl acetate, ethyl acetate and n-butyl acetate in the temperature (298.15, 293.15, 298.15, 303.15 and 308.15) K", J. of Solution Chemistry., 2013, 42(10).

17. Resa, J.M., Gonzalez, C., Delandaluce, S.O. and Lanz, J., "Vapor liquid equilibrium of binary mixtures containing diethyl amine + diisopropyl amine, diethyl amine + dipropyl amine, and chloroform + diisopropyl amine at $101.3 \mathrm{kpa}$, and vapor pressures of dipropyl amine", $J$. Chem. Eng. Data., 2000, 45, 867-871.

18. Kumar, P.G., Venkatesu, P., Rao, M.V.P., Lee, M.J. and Lin, H.M., "Isobaric (vapour + liquid) equilibrium for $\mathrm{N}$-methyl-2-pyrrolidone with branched alcohols", J. of Chem. Thermodyn., 2009, 184-188.

19. Oswal, S.L., Oswal, P., Gardas, R.L., Patel, S.G. and Shinde, R.G., "Acoustic, volumetric, compressibility and refractive properties and reduction parameters for the ERAS and flory models of some homologous series of amines from 298.15 to 328.15 K", Fluid Phase Equilib., 2004, 216, 33-45.

20. Lampreia, I.M.S. and Barbosa, E.F.G., "Partial molar volumes of secondary amines in methanol, specific interactions", Fluid Phase Equilib., 1992, 71, 125-142.

21. Henni, A., Hromek, J.J., Tontiwac Hwuthlkul, P. and Chakma, A., "Volumetric properties and viscosities for $\mathrm{N}$-methyl-2-pyrrolidone solutions from 25 to 70 'C", J. Chem. Eng. Data., 2004, 49, 231-234.

22. Sastry, N. and Valand, M.K., "Densities, viscosities and relative permittivities for pentan +1 -alcohols $(C 1$ to $\mathrm{C} 12)$ at 298.15 K”, J. Chem. Eng. Data., 1998, 43, 152-159.

23. Yang, C., Lai, H., Liu, Z. and Maj, P., "Ultrasonic and viscometric study of molecular interaction in binary mixtures with 1-propanol, 2- propanol, 2-methyl-1- propanol and 2-methyl-2- propanol at different temperatures", J. Chem. Eng. Data., 2006, 51, 1345-1351.

24. Riddick, J.A., Bunger, W.B. and Sakano, T.K., Organic Solvents: Physical and Methods of
Purification, 4th ed., John Wiley and Sons, New York, 1986.

25. Sastry, N.V., Patel, S.R. and Soni, S.S., "Densities, speeds of sound, excess molar volumes and excess isentropic compressibilities at $\mathrm{T}(298.15$ to 308.15$) \mathrm{K}$ for methylmethacrylate + 1-alkanols (1-butanol, 1-pentanol and 1-hexanol) + cyclohexane + benzene + toluene + p-xylene and + ethylbenzene", J. Chem. Eng. Data., 2011, 56, 142-152.

26. Lide, R.D., Handbook of Chemistry and Physics, CRC press: Boca Raton, FL, Section 6., 2000,180-184.

27. Mehra, R., Application of refractive index mixing rules in binary system of hexadecane and heptadecane with n-alkanols at different temperatures", Proc. Indian Acad. Sci., 2003, 115, 147-154.

28. Al-Jimaz, A.S., Al-Kandary, J.A. and AbduLatif, A.M., "Viscosities and densities for binary mixtures of phenetole with 1-pentanol, 1-hexanol, 1-heptanol, 1-octanol, 1-nonanol and 1-decanol at different temperatures", Fluid Phase Equilib., 2004, 218, 247-260.

29. Venkatakshmi, V,, Gowrisankar, M., Venkateswarlu, P. and Reddy, K.S., "Density, ultrasonic velocity, viscosity and their excess parameters of the binary mixtures of 2-methyl aniline with 1-alkanols (C3-C8) at different temperatures", International J. of Physics, 2013, 3, 33-44.

30. Dewan, R.K., Methta, S.K., Paragshar, R. and Bala, K., "Topological investigations on the association of alkanols: excess volume of pyridine-alkanol (C1-C10) mixtures", J. Chem. Faraday Trans, 1991, 87(10), 1561-1568.

31. Tejraj, M., Aminabhavi, Mrityunjay,l., Aralaguppi, Shivaputrappa, B., Harogoppad and Ramachandra, H., Balundgi, "Densities and viscosities, refractive indices, and speeds of sound for methyl acetoacetate + aliphatic alcohols (C1-C8)", J. Chem. Eng. Data., 1993, 38, 31-39.

32. Al-Kandary, J.A., Al-Jimaz, A.S. and AbduLatif, A.M., "Densities and viscosities, speeds of sound, and refractive indices of binary mixtures of tetrahydrofuran with 1-hexanol, 1-heptanol, 1-octanol, 1-nonanol and 1-decanol at (298.15, 303.15 308.15 and 313.15) K", Physics and Chemistry of Liquids, 2009, 47(2), 210-224. 
33. Al-Jimaz, A.S., Al-Kandary, J.A., Abdul-Hag M., Abdul-Latif, A.M., "Acoustical and excess properties of \{chlorobenzene +1 -hexanol, or 1-heptanol, or 1-octanol, or 1-nonanol or 1-decanol\} at (298.15, 303.15308.15 and 313.15) K', J. Chem. Eng. Data., 2007, 52, 206-214.

34. Dzida, M., "Study of the effects of temperature and pressure on the thermodynamic and acoustic properties of pentan-1-ol, 2-methyl-2butanol and cyclopentanol in the pressure range from (0.1 to100) from (293.15 to 318.15) K", J. Chem. Eng. Data., 2009, 54, 1034-1040.

35. Lomet, S.B., Bawa, M.J., Lande M. K., and Arbad, B.R., "Densities and viscosities of binary liquid mixtures of 2-butanone with branched alcohols at (293.15 to 313.15) K", J. Chem. Eng. Data., 2009, 54, 127-130.

36. Brocos, P., Pineiro, A., Bravo, R. and Amigo,
A., "Refractive indices, molar volumes and molar refractions of binary liquid mixtures", Phys. Chem., 2003, 5, 550-557.

37. Pal, A. and Kumar, R., "Excess molar volumes and viscosities for binary mixtures of 2-propoxyethanol and 2-isopropoxyethanol with propylamine and dipropylamine at (298.15, 308.15 to 318.15) K", J. Chem. Eng. Data., 2001, 46, 933-938.

38. Radovic, I.R., Kijevcaninand, M.J. and Tasic, A.Z., "Densities and excess molar volumes of alcohol + cyclohexylamine mixtures", Serbian. Chem. Soc., 2009, 74(11), 1303-1318.

39. Redlich, O. and Kister, A.T., "Algebraic representation of thermodynamic properties and classification of solution", Ind. Eng. Chem., 1948, 40, 345-348. 